\title{
Controllable methane hydrate formation through trace carbon dioxide charging
}

\author{
Yuanmei Song ${ }^{\mathrm{a}, \mathrm{b}}$, Fei Wang ${ }^{\mathrm{a}}$, Guoqiang Liu ${ }^{\mathrm{c}}$, Shengjun Luo ${ }^{\mathrm{a}, *}$, Rongbo Guo ${ }^{\mathrm{a}, *}$

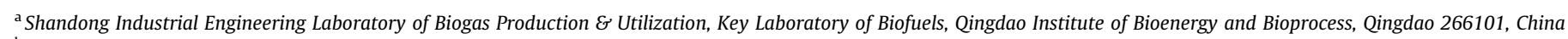 \\ ${ }^{\mathrm{b}}$ University of Chinese Academy of Sciences, Beijing 100049, China

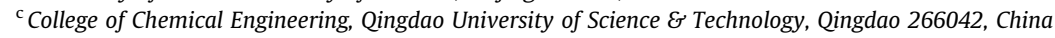

\section{H I G H L I G H T S}

- Methane hydrate formation was accelerated by increasing $\mathrm{CO}_{2}$ content.

- The easier formed $\mathrm{CO}_{2}$ nuclei triggered faster hydrate nucleation.

- Addition of a certain amount of $\mathrm{CO}_{2}$ in induction period triggered fast methane hydrate growth stage.

\section{G R A P H I C A L A B S T R A C T}
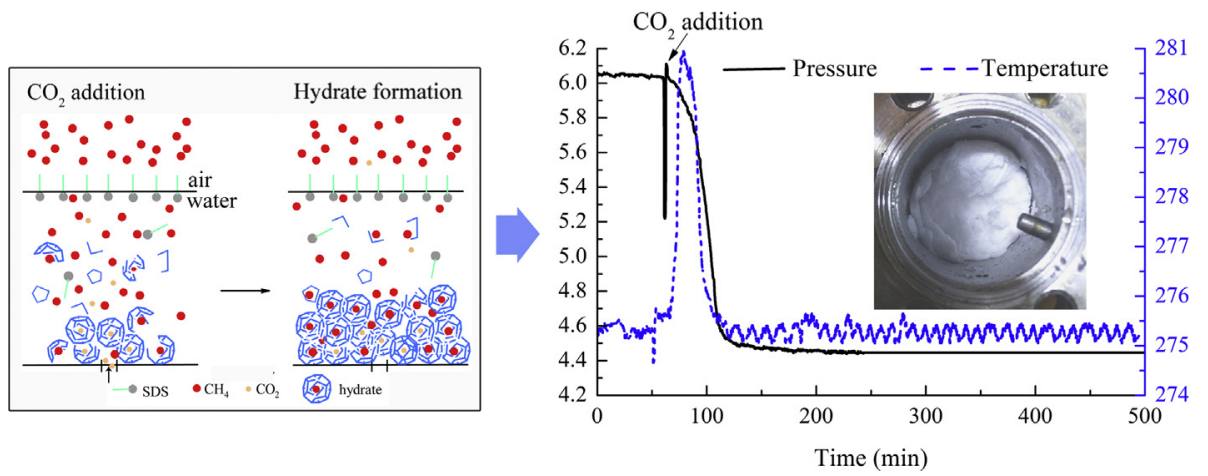

\begin{abstract}
A B S T R A C T
An initial method to efficiently control methane hydrate formation process was investigated in this work. This method included an in-situ injection of a small amount of $\mathrm{CO}_{2}$ into the reactor during the nucleation stage to explore hydrate formation in $0.5 \mathrm{mmol} / \mathrm{L}$ sodium dodecyl sulfate (SDS) solutions. Results showed that charging $\mathrm{CO}_{2}$ higher than $2 \%$ in the mixed gases could induce immediate methane hydrate growth stage. Furthermore, when $3 \% \mathrm{CO}_{2}$ was injected into the reaction system at different time points, the times required for hydrate formation were all shortened significantly. Especially at the injection points of more than $30 \mathrm{~min}$, the subsequent crystals growth began immediately after $\mathrm{CO}_{2}$ injection. Besides, the formed hydrates tended to aggregate in the vicinity of $\mathrm{CO}_{2}$ injection zones. Such promotion effect was possibly caused by the triggering effect of preferentially formed $\mathrm{CO}_{2}$ hydrates in the reaction system. This work provides a novel and simple method to control hydrate formation process, which is of great significance to the transportation and storage of natural gas.
\end{abstract}

(c) 2017 Elsevier Ltd. All rights reserved.
* Corresponding authors at: Qingdao Institute of Bioenergy and Bioprocess Technology, Chinese Academy of Sciences, No. 189 Songling Road, Qingdao, Shandong Province 266101, China.

E-mail addresses: luosj@qibebt.ac.cn (S. Luo), guorb@qibebt.ac.cn (R. Guo).

\section{Introduction}

Gas hydrates are categorized as clathrates, which are nonstoichiometric crystalline compounds composed of external cages formed by hydrogen-bonded water molecules and enclosed guest gases such as $\mathrm{CH}_{4}, \mathrm{C}_{2} \mathrm{H}_{6}, \mathrm{CO}_{2}$ etc. [1]. Attracted by the high gas storage of the hydrate as well as the high safety and economy in the methane formation process, many researchers have regarded the 
hydrate-based technology for storage and transportation of natural gas as a promising method [2-4]. However, the long induction time and low growth rate during the hydrate formation restricted the wide applications of hydrate-based technologies in industries [5]. Searching for efficient ways to overcome those obstacles has stimulated increasing interest of researchers who contributed a lot to kinetics and thermodynamics studies for promoting the hydrate formation process. Both physical [6-8] and chemical methods [9] were verified as effective ways to improve the methane hydrate formation, among which sodium dodecyl sulfate (SDS) was the most efficient and economical accelerant for hydrate growth rate [10]. Nevertheless, the physical ways are economically infeasible as they require higher energy input and extra production cost. Chemical promoters are difficult to recover as well as cause serious contaminations. Besides, the application of methane hydrate is limited by large amounts of foam produced during hydrate dissociation with high-concentrated SDS. Therefore, it is urgent to develop more efficient and economical ways to improve the hydrate formation.

As natural gas is a gaseous mixture composed of primary gas of methane and a small number of other gases such as carbon dioxide, propane, ethane etc., each component may affect the kinetic and thermodynamic properties of natural gas hydrate [11]. Thus, it is a possible and potential way to apply other gaseous hydrate formers to accelerate methane hydrate formation. For example, $\mathrm{C}_{3} \mathrm{H}_{8}$ molecules tend to occupy large cavities to stabilize the hydrate structure and the as-formed $\mathrm{C}_{3} \mathrm{H}_{8}$ hydrates could be the accelerants to help faster nucleation of other crystals [12,13]. Some researches on the $\mathrm{CH}_{4} / \mathrm{CO}_{2}$ mixture were mainly aimed at the separation technology to purify biogas or the extraction of $\mathrm{CH}_{4}$ accompanied by sequestration of $\mathrm{CO}_{2}$ simultaneously. Decreased equilibrium pressure with the increasing $\mathrm{CO}_{2}$ concentration at a specific temperature was beneficial to hydrate formation in view of thermodynamics [14-16]. The work by Yan Sun et al. [17] showed that $\mathrm{CO}_{2}$ hydrates could formed firstly, followed by methane hydrates formation when the partial pressure of methane reached the formation pressure. From the point of dynamic point, studies on the mechanism of $\mathrm{CH}_{4} / \mathrm{CO}_{2}$ mixed gas hydrate indicated that the growth rate of hydrate was enhanced by high $\mathrm{CO}_{2}$ concentration and the induction time decreased linearly with concentration $[16,18,19]$. Theoretically, the solubility of $\mathrm{CO}_{2}$ is about 10 times greater than that of $\mathrm{CH}_{4}$ in the gas-liquid-hydrate ternary system, which also make it easier for $\mathrm{CO}_{2}$ to form hydrate if the binary gas of $\mathrm{CO}_{2}$ and $\mathrm{CH}_{4}$ coexist in the liquid phase [20]. Structurally, $\mathrm{CO}_{2}$ tend to occupy large cages $4^{3} 5^{6} 6^{3}$ while $\mathrm{CH}_{4}$ molecule occupy small cages $5^{12}$ in the hydrates which determined the stable structure in spite of the same structure of sI for both carbon dioxide and methane [18]. Moreover, the hydrates containing an amount of $\mathrm{CO}_{2}$ would be denser than pure methane hydrate and the mixed gas hydrate presented best stability than pure methane hydrate or carbon dioxide hydrate [21].

On the premise that the existing $\mathrm{CO}_{2}$ hydrate crystal in the reaction system can initiate the nucleation of methane hydrate, it was suggested that the methane hydrate formation process can be controlled by injecting an amount of $\mathrm{CO}_{2}$. In view of practical use of natural gas hydrate, the $\mathrm{CO}_{2}$ content was usually controlled within $5 \%$. Thus, in this work, the effect of trace of $\mathrm{CO}_{2}$ addition on the methane hydrate formation was investigated. In addition, the controlling role of the $\mathrm{CO}_{2}$ during the hydrate formation process through charging $\mathrm{CO}_{2}$ into the reactor at different time points was also explored.

\section{Experimental}

\subsection{Materials}

Methane (purity $>99.99 \%$ ) and mixed gas ( $1 / 3$ carbon dioxide and $2 / 3$ methane) were provided by Heli Gas Company; sodium dodecyl sulfate (SDS, A.R.) (purity > 99.8\%) was provided by Xiya Reagent Company; The deionized water used in this experiment was laboratory-made with conductivity of $1.1 \pm 0.1 \mu \mathrm{s} / \mathrm{cm}$ at $298.15 \mathrm{~K}$.

\subsection{Hydrate formation process}

The established set-up applied in this experiment is described in Fig. 1. The main components include two piston containers with the volume of $1 \mathrm{~L}$ and one reactor made of $316 \mathrm{~L}$ stainless steel (roughness $\leqq 0.2 \mu \mathrm{m}$ ) with volume capacity of $200 \mathrm{~mL}$. The internal pressure and temperature variations were monitored and recorded by the computer through a thermocouple and a pressure transducer. The containers and reactor were immersed in a temperature-controlled liquid bath made of glycol and water (volume ratio of $1: 2$ ). The reaction temperature was controlled at $275.15 \mathrm{~K}$ with the accuracy of $0.01 \mathrm{~K}$.

The reactor was firstly washed and rinsed with deionized water for three times in order to remove residual hydrates. Methane was pressurized into piston containers in advance to reach the reaction temperature in case pressure changes during the cooling process. Then $30-\mathrm{mL}$ SDS solution $(0.5 \mathrm{mmol} / \mathrm{L})$ was injected into the reactor and the reactor was flushed with methane to evacuate air from the cell. Pure methane of $6 \mathrm{MPa}$ was charged into reactor after the temperature inside the reactor reached the required temperature of $275.15 \mathrm{~K}$. When $\mathrm{CO}_{2}$ was required during the reaction process, the methane in the reactor was released slowly to a certain value. Subsequently, the mixed gases of $\mathrm{CO}_{2} / \mathrm{CH}_{4}$ was charged also to $6 \mathrm{MPa}$ through the channel connected to the reactor, by which way the total pressure for hydrate reaction could maintain constant. When reaction was completed, the reactor was depressurized quickly while the temperature was decreased to reduce hydrate dissociation. Then the reactor was opened and the hydrates morphology was observed by taking photos.

\section{Results and discussion}

\subsection{Pure methane hydrate formation process}

As a common hydrate promoter for both carbon dioxide and methane hydrate, the SDS with a low concentration of $0.5 \mathrm{mmol} /$ $\mathrm{L}$ was chosen in this work to get rapid formation process. Taking the stochastic nucleation into consideration, every experiment was repeated for three times. The pressure and temperature evolutions in the pure methane hydrate formation process in the SDS solutions or water were shown in Fig. 2. When the hydrate started to form and grow, the pressure decreased with time owing to the gas consumption which was called the hydrate growth stage (noted on the blue line in Fig. 2). Clearly, more than 300 min of stagnation period always preceded the hydrate growth stage, during which almost no gas was consumed. This stage was named as induction period related to the hydrate nucleation process (as marked on the blue curve in Fig. 2) [22]. Compared with deionized water where no pressure drop was observed within $10 \mathrm{~h}$, the hydrate formations in the SDS solutions were all completed in $400 \mathrm{~min}$. Thus, using $0.5 \mathrm{mmol} / \mathrm{L}$ SDS solution improved hydrate formation greatly. Moreover, the rapid hydrate growth led to the sharp temperature increase due to the exothermal reaction. However, the long induction times ranging from 300 to 400 min were still unfavorable in the practical utilization of methane hydrate.

The hydrates morphology and growth pattern in the reactor in the SDS solution was shown in Fig. 2(B). The mushy methane hydrates showed upward growth pattern and almost covered the whole sidewall of the reactor, which was possibly caused by the capillary effect of porous hydrate crystals [23,24]. However, the 


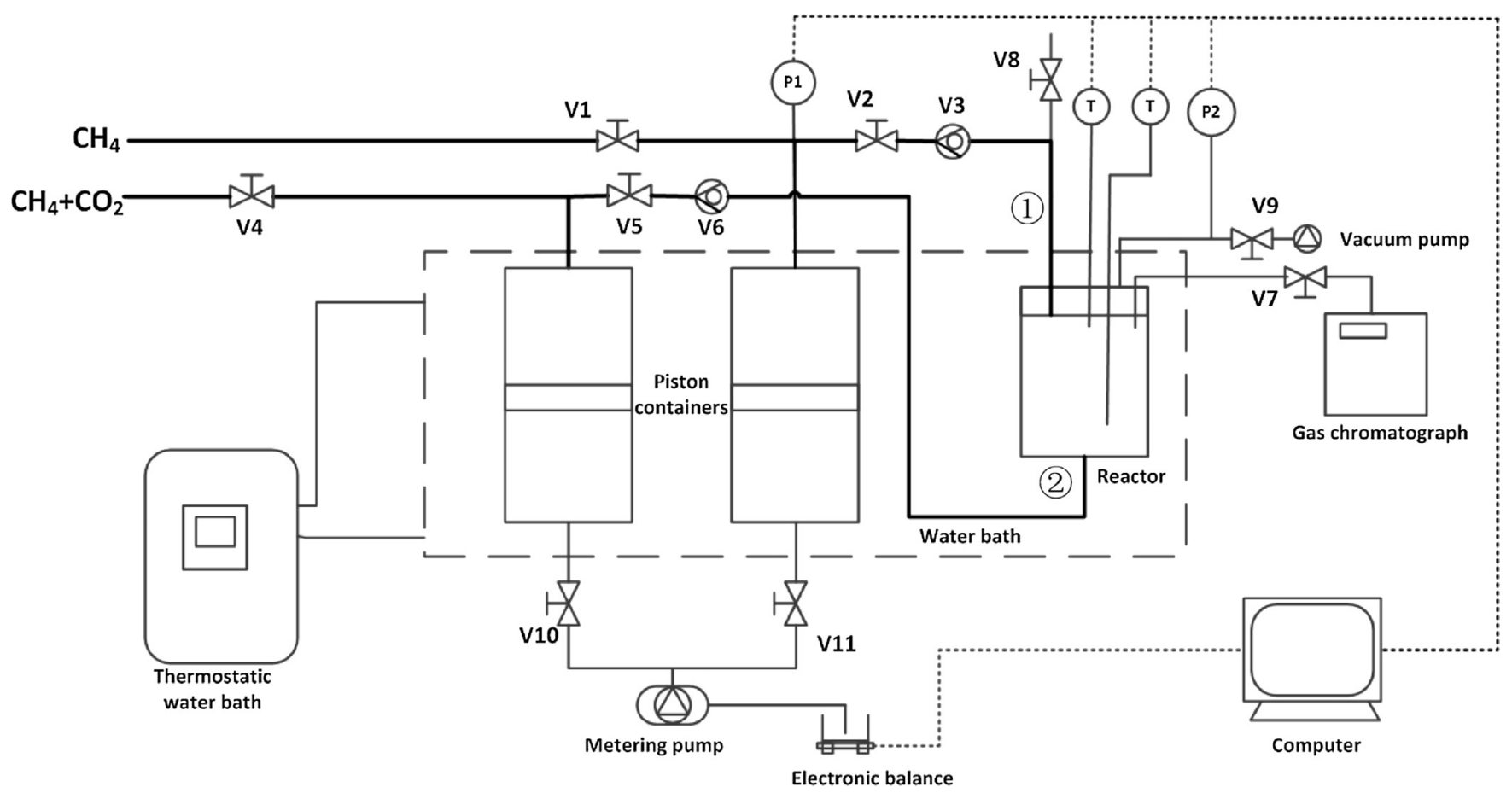

Fig. 1. Schematic diagram for experimental set-up: (1)-top channel (2)-bottom channel for gas charge.

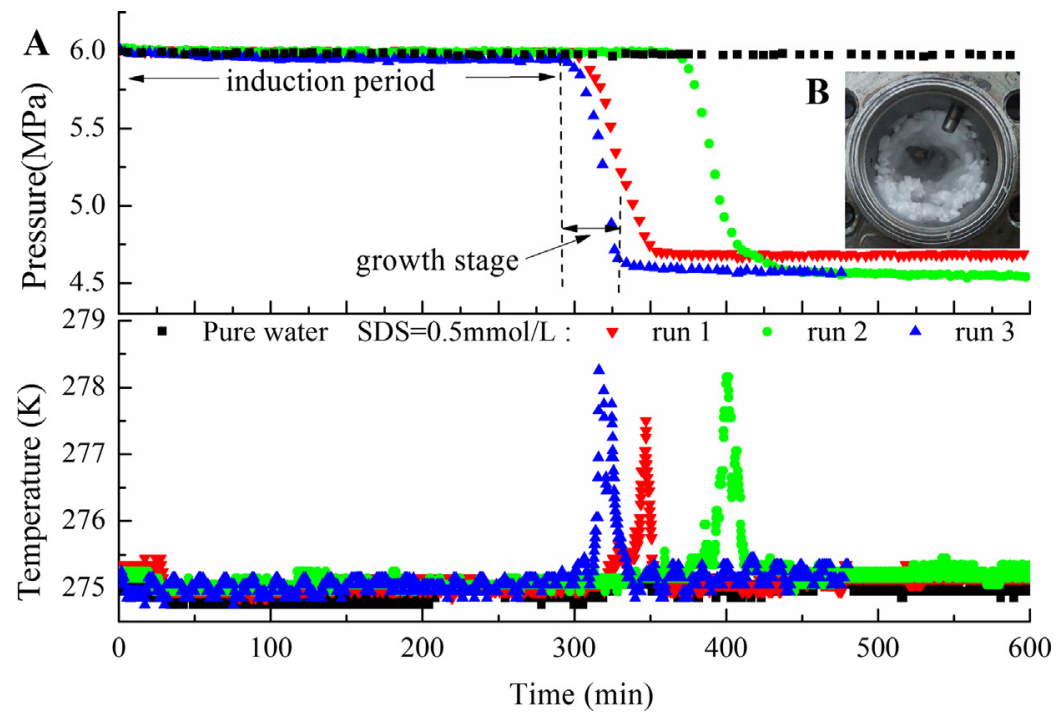

Fig. 2. (A) P/T versus time in methane hydrate formation process; (B) Methane hydrates morphology in the reactor with SDS solutions.

hydrates adhered to the sidewall are hard to be removed and the less dense hydrates may also cause difficulties in compaction during hydrate transportation and storage.

In order to exclude the effect of bubbling agitation caused by $\mathrm{CO}_{2} / \mathrm{CH}_{4}$ mixture injection through the bottom channel connected to the reactor bottom, the methane hydrate formation was also investigated when the same amount of $\mathrm{CH}_{4}$ as that of $\mathrm{CO}_{2}$ was injected at $60 \mathrm{~min}$. Fig. 3 was the results of pressure and temperature changes in the hydrate formation with the addition of $2 \%, 3 \%$, and $4 \% \mathrm{CH}_{4}$ respectively. The pressure kept steady with little gas consumption within 800 min when $2 \%$ or $3 \% \mathrm{CH}_{4}$ was used, except that the hydrate formed at about 650 min with $4 \% \mathrm{CH}_{4}$ injection. These results were almost consistent with the results in Fig. 2 where pure methane hydrate took long time to react or no reaction happened. Therefore, the bubbling effect caused by injecting methane from the bottom channel had little influence on the methane hydrate formation.

\subsection{Effect of $\mathrm{CO}_{2}$ content on hydrate formation}

To avoid the influences of pressure changes on the methane hydrate formation, the injection of a certain amount of $\mathrm{CO}_{2}$ was accompanied by release of the same amount of methane in the reactor at the time point of $60 \mathrm{~min}$. The pressure evolution in the hydrate formation and the hydrate morphology in the reactor with the increasing $\mathrm{CO}_{2}$ content were described in Fig. 4. When the injected $\mathrm{CO}_{2}$ fraction was lower than $2 \%$, no pressure drop was observed within $300 \mathrm{~min}$ in the first three curves which evolved 


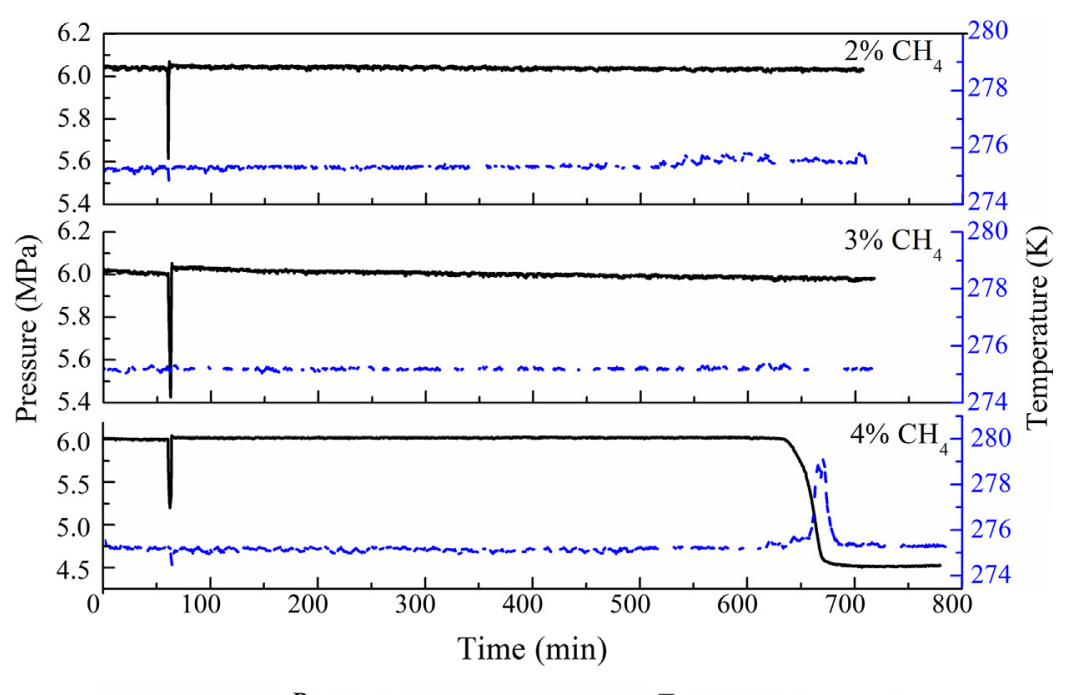

$\longrightarrow$ Pressure $\quad----$ Temperature

Fig. 3. $\mathrm{P} / \mathrm{T}$ curves versus time in the hydrate formation process with $2 \%, 3 \%$ and $4 \% \mathrm{CH}_{4}$ injection at $60 \mathrm{~min}$.

in a similar way with the curves for the $0.5 \mathrm{mmol} / \mathrm{L}$ SDS in Fig. 2. It indicated that the hydrate formation may not be affected by lowcontented $\mathrm{CO}_{2}$. However, with $\mathrm{CO}_{2}$ content elevated to higher than $2 \%$, there was an obvious pressure decrease immediately after $\mathrm{CO}_{2}$ injection, resulting in short hydrate formation process.

Under the experimental conditions, the partial pressure of $\mathrm{CO}_{2}$ just ranged from 0 to $0.24 \mathrm{MPa}$ that was much smaller than the required pressure for the $\mathrm{CO}_{2}$ formation $(1.6 \mathrm{MPa}$ at $275.15 \mathrm{~K}$ [25]). Thus the thermodynamic factors that affecting hydrate formation were not considered in this work. Taking dynamic promotion into consideration, $\mathrm{CO}_{2}$ uptake by gas hydrate formation proceeds more quickly than the methane uptake due to the higher solubility and easier nucleation of $\mathrm{CO}_{2}$ molecules [20]. Then the fast formed $\mathrm{CO}_{2}$ hydrate crystals in the reaction system could act as seeds for inducing the subsequent formation of methane hydrates, which was also further discussed in session 3.3. It could be deduced from Fig. $4 \mathrm{D}-\mathrm{F}, \mathrm{CO}_{2}$ at the content of higher than $2 \%$ was sufficient to enhance hydrate formation process.

The blue curves in Fig. 4 represent the temperature evolutions with time in the hydrate formation. In the either hydrate nucleation stage or the time after completion of hydrate formation, the recorded temperature went through steady fluctuation in an allowable range of $275.15 \pm 0.5 \mathrm{~K}$. In Fig. $4 \mathrm{E}-\mathrm{F}$, even at the point of $\mathrm{CO}_{2}$ injection where temperature drop was evident due to methane release, the temperature variations within $0.5 \mathrm{~K}$ were assumed negligible. Besides, the sharp increase in temperature curve at hydrate growth stage caused by exothermic reaction was one characteristic parameter for the fastest hydrate growth. Seen from Fig. 4A-F, the peak value of temperature was growing gradually with the increasing $\mathrm{CO}_{2}$ content in the gas phase, which kept consistent with the highest hydrate growth rate from the steepest slope of pressure curves in the hydrate growth. Thus, the addition of a trace of $\mathrm{CO}_{2}$ in the reaction system may also be conducive to the hydrate growth.

The hydrate growth patterns and morphologies with different $\mathrm{CO}_{2}$ contents were depicted in Fig. $4 \mathrm{~A}^{\prime}-\mathrm{F}^{\prime}$. At $\mathrm{CO}_{2}$ concentration lower than $2 \%$, the formed hydrates covered the most part of sidewall of the reactor similar to the phenomenon in Fig. 2. In contrast, the hydrate mainly massed at the bottom when $\mathrm{CO}_{2}$ higher than $2 \%$. Thus, the hydrate growth pattern may be influenced by the addition of a certain amount of $\mathrm{CO}_{2}$ in the reaction system.
To deeper understand the promotion effect caused by trace $\mathrm{CO}_{2}$ charging, another series of experiments were conducted where $2 \%$, $3 \%$ and $4 \%$ of $\mathrm{CO}_{2}$ was injected respectively at $60 \mathrm{~min}$ through the upper channel instead of bottom channel connected to the reactor. The pressure changes and hydrate morphologies in the reactor were presented in Fig. 5.

The pressure changes in Fig. $5 \mathrm{~A}-\mathrm{C}$ exhibited high similarity with that in Fig. 4D-F. The hydrate formation processes were completed within $80 \mathrm{~min}$ after $\mathrm{CO}_{2}$ injection through upper channel. This gave further proof that the hydrates formation could be efficiently improved by injection of a small amount of $\mathrm{CO}_{2}$ regardless of the injection positions. However, the hydrates were presented as crust structure to cover the sidewall of the reactor in Fig. $5 A^{\prime}-C^{\prime}$, which was totally different from the hydrates morphologies in Fig. $4 \mathrm{D}^{\prime}-\mathrm{F}^{\prime}$. As the injected $\mathrm{CO}_{2}$ from top of the reactor initially dissolved at the gas-liquid-wall interface, the local concentration of $\mathrm{CO}_{2}$ would be supersaturated. Then $\mathrm{CO}_{2}$ hydrate crystals preferentially formed at this place followed by the second methane hydrate formation in the vicinity of the interface. The similar phenomenon was also reported by Ricaurte [26] who observed in the sapphire windows of the reactor that the gas hydrates tended to grew around the position where tetrahydrofuran(THF) was injected. With the aid of $\mathrm{DS}^{-}$anions absorbed on the hydrate surface, the porous hydrate at the gas-liquid-wall interface kept high exchange area between the water and gas phase [23], resulting in the final hydrates crust adhered to the sidewall in Fig. $5 \mathrm{~A}^{\prime}-\mathrm{C}^{\prime}$. For the same reason, the first-formed $\mathrm{CO}_{2}$ crystals also resulted in formation of $\mathrm{CH}_{4}$ hydrates at the reactor bottom (Fig. 4 $\mathrm{D}^{\prime}-\mathrm{F}^{\prime}$ ) based on the local-concentrated $\mathrm{CO}_{2}$ when the sufficient $\mathrm{CO}_{2}$ was injected from the bottom channel. The analysis of the differences in the hydrate morphologies provided indirect evidence that the as-formed $\mathrm{CO}_{2}$ hydrate crystals in the reaction system could trigger the second methane hydrate formation.

\subsection{Controlling hydrate formation process through $\mathrm{CO}_{2}$ injection}

To guarantee high calorific value of gaseous fuel, the volume fraction of $\mathrm{CO}_{2}$ component in the standard natural gas should be controlled within $3 \%$ at $101.325 \mathrm{kPa}$ and $20^{\circ} \mathrm{C}$ [27]. Therefore, to explore controllable role of $\mathrm{CO}_{2}$ injection on the gas hydrate formation process, the $\mathrm{CO}_{2}$ content in the binary gas of $\mathrm{CH}_{4} / \mathrm{CO}_{2}$ was set 

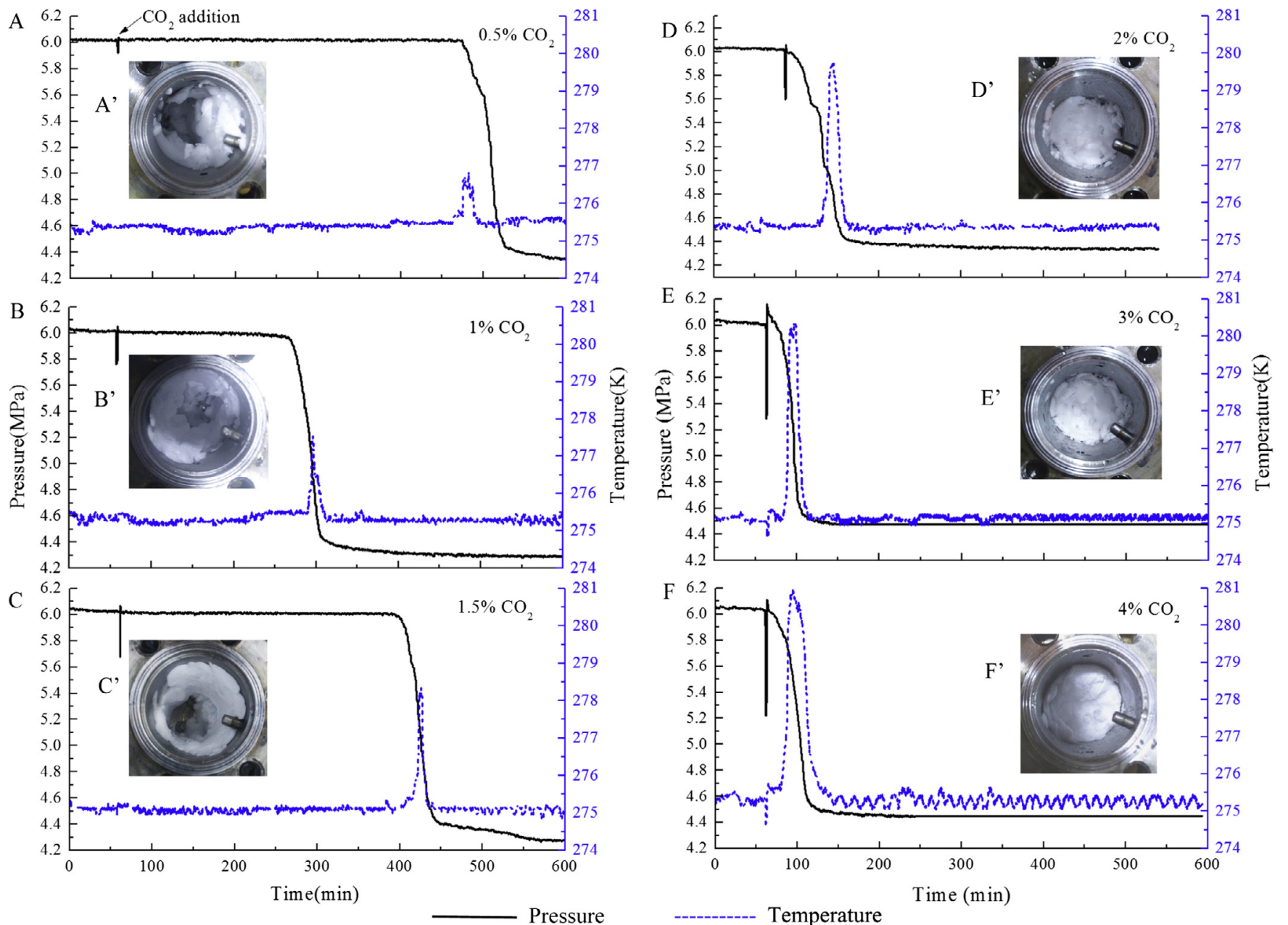

Fig. 4. $\mathrm{P} / \mathrm{T}$ curves versus time in the hydrate formation process with various $\mathrm{CO}_{2}$ contents and the hydrate morphology and growth pattern in the reactor.

A

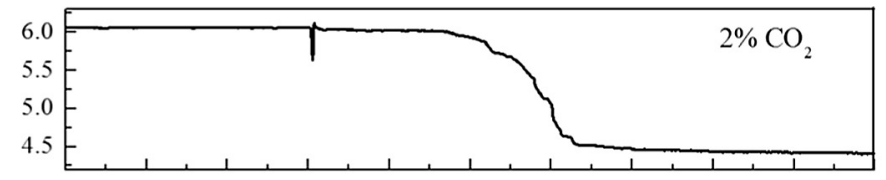

B

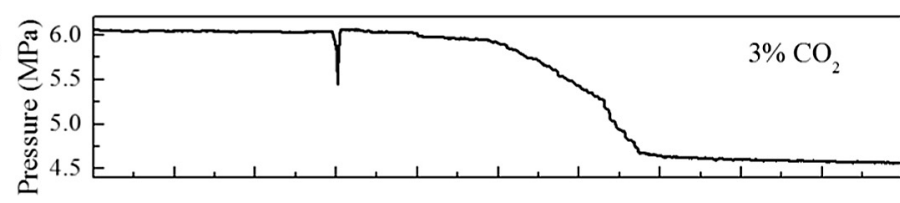

C

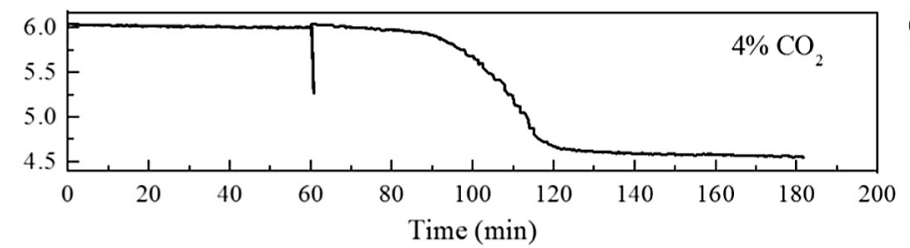

$\mathrm{A}^{\prime}$

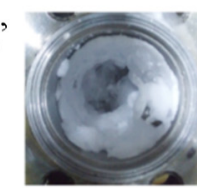

$B^{\prime}$

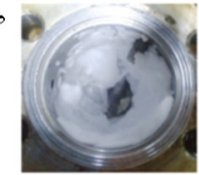

$C^{\prime}$

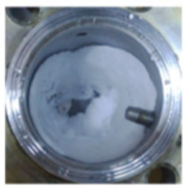

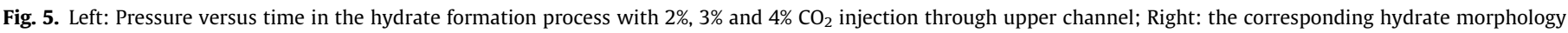
and growth pattern in the reactor.

as $3 \%$. With $\mathrm{CO}_{2}$ charging at different time points prior to hydrate growth stage, the hydrate formation processes were observed through the pressure evolutions in Fig. 6. when $\mathrm{CO}_{2}$ was charged in the reactor initially, the pressure showed no tendency to descend until after approximate $75 \mathrm{~min}$. With $\mathrm{CO}_{2}$ addition time point postponed from 15 to $120 \mathrm{~min}$, the duration time for the pressure plateau was shrunk gradually. When the addition time point was more than $30 \mathrm{~min}$, the pressure presented more obvious decrease immediately after $\mathrm{CO}_{2}$ addition. This phenomenon demonstrated that the $\mathrm{CO}_{2}$-addition-time points may have influence on the 


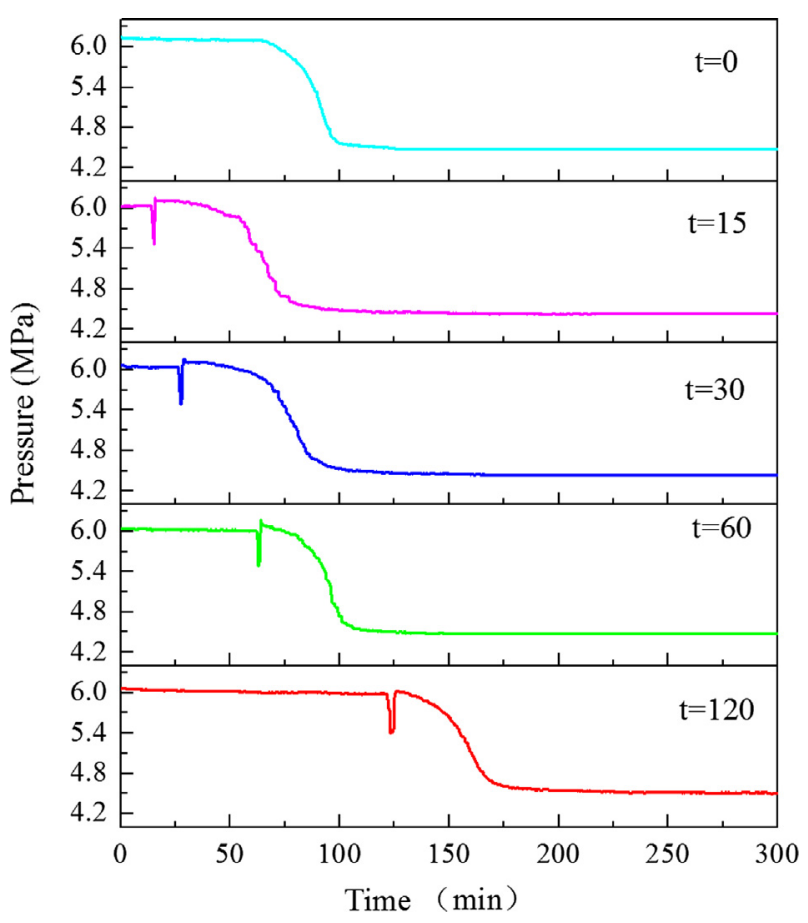

Fig. 6. Pressure evolutions during hydrate formation with different time points of $\mathrm{CO}_{2}$ addition in $0.5 \mathrm{mmol} / \mathrm{L}$ SDS solutions (initial pressure was $6 \mathrm{MPa}$, temperature was $273.15 \mathrm{~K})$. behaviors of hydrate formations. In order to further investigate the impact of the $\mathrm{CO}_{2}$ injection time on the hydrate behaviors, we define $\tau$ as the duration time for hydrate formation after $\mathrm{CO}_{2}$ addition, which was used to characterize the follow-on hydrate formation process. Given the stochasticity of hydrate formation, every experiment was carried out for three repetitions.

The results for $\tau$ in repeated hydrate formations were listed in Table 1 . The average value of $\tau$ after $\mathrm{CO}_{2}$ injection decreased from 90 to $32 \mathrm{~min}$ when the injection point increased from 0 to $120 \mathrm{~min}$. Combined with the curves in Fig. 6, when the $\mathrm{CO}_{2}$ injection point was larger than $30 \mathrm{~min}$, the hydrate growth stage almost occurred immediately after $\mathrm{CO}_{2}$ charge. Thus, the duration time $\tau$ can be assumed as the hydrate growth stage. This growth stage tended to be shortened with increasing injection point from 30 to $120 \mathrm{~min}$, indicating that elevating the injection point facilitated the hydrate growth.

According to the labile cluster nucleation hypothesis proposed by Sloan et al. [1] and the model established by van der Waals and Platteeuw [28], ring structures of pentamers and hexamers produced by water molecules always existed in liquid phase and provided cavities as adsorbent, which would further form labile clusters around dissolved guest molecules until grow to a critical radius. Just as described in Fig. 7(A), the cagelike structures would form and decompose constantly in the nucleation period and longer time contributed to more labile and larger clusters structures in the aqueous phase [29].

Uchida et al. [30] concluded that $\mathrm{CO}_{2}$ molecules could be preferably taken up by the hydrates in spite of the higher initial fraction of $\mathrm{CH}_{4}$ in the binary gas mixture monitored by the Raman spec-

Table 1

The duration time of hydrate formation after $\mathrm{CO}_{2}$ injection at different time points.

\begin{tabular}{|c|c|c|c|c|c|}
\hline \multirow[t]{2}{*}{ Addition time point (min) } & \multicolumn{5}{|c|}{$\tau(\min )$} \\
\hline & $1 \mathrm{st}$ & 2nd & $3 r d$ & $\mathrm{av}^{\mathrm{a}}$ & $\mathrm{sd}^{\mathrm{b}}$ \\
\hline 0 & 95 & 86 & 90 & 90 & 4 \\
\hline 15 & 60 & 68 & 85 & 71 & 10 \\
\hline 30 & 54 & 75 & 51 & 60 & 11 \\
\hline 60 & 61 & 45 & 37 & 48 & 10 \\
\hline 120 & 32 & 22 & 43 & 32 & 9 \\
\hline
\end{tabular}

a av-average.

b sd-standard deviation.

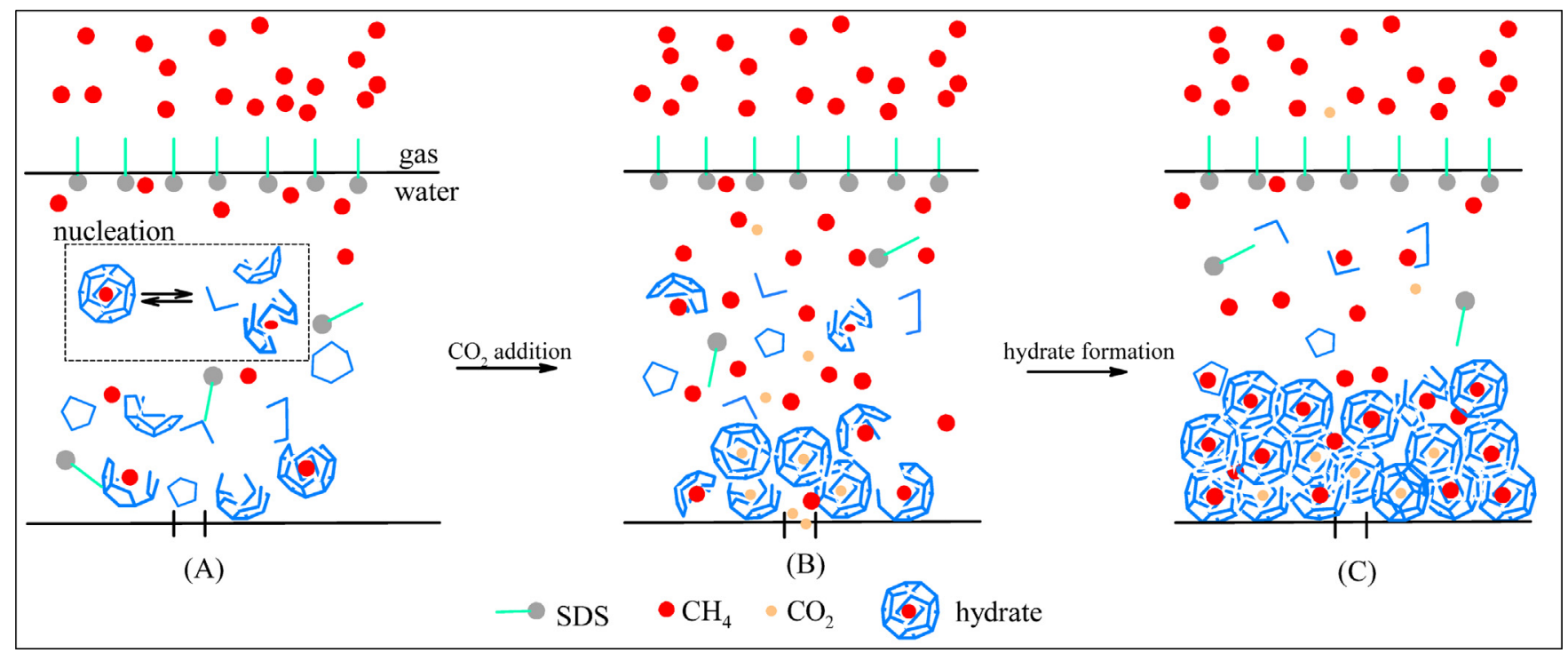

Fig. 7. Schematic diagram for hydrate formation process with $\mathrm{CO}_{2}$ addition. 
troscopy and gas chromatography. Some kinetic models showed that $\mathrm{CO}_{2}$ played a key role in stabilizing the hydrate structure in the newly formed hydrate nuclei and higher relative ability of $\mathrm{CO}_{2}$ molecules to get enclathrated within the cavities [31,32]. With the higher formation affinity and the higher stability of $\mathrm{CO}_{2}$ hydrate [33], $\mathrm{CO}_{2}$ hydrate crystals could form quickly once a trace of $\mathrm{CO}_{2}$ was charged from the reactor bottom, which triggered the faster formation of critical nuclei (Fig. 7B). Then the methane hydrates started to grow and aggregate around the $\mathrm{CO}_{2}$ hydrate crystals (Fig. 7C). This also can explain the hydrate morphologies shown in Figs. 4 and 5. Therefore, based on enough hydrate clusters formed in the aqueous phase after methane charge, the injection of a trace of $\mathrm{CO}_{2}$ could play a switch-like role in triggering the hydrate growth. The later the injection time points was, the larger size and more numbers of hydrate clusters obtained, which also contributed more to the fast hydrate formation. Thus, the hydrate formation process was progressively accelerated with $\mathrm{CO}_{2}$ injection after progressively longer methane charging times. However, the detailed mechanism of these specific behaviors of mixed hydrates in the formation process still require further studies from the microscopic view by more characteristic or modeling methods.

\section{Conclusion}

This is the first study to investigate the triggering effect of a trace of $\mathrm{CO}_{2}$ on the methane hydrate formations. Results showed that $\mathrm{CO}_{2}$ with content lower than $2 \%$ had little effect on the hydrate formation process while the process was accelerated obviously by further elevating $\mathrm{CO}_{2}$ content. Due to the preferential $\mathrm{CO}_{2}$ hydrate crystals formation in the SDS solutions, the as-formed crystals could initiate the second hydrate formation of methane. Thus, charging $3 \% \mathrm{CO}_{2}$ at different injection time points triggered subsequent faster hydrate formations. And longer $\mathrm{CO}_{2}$ injection points after methane charge was more beneficial to decrease the time required for methane hydrate formation. Moreover, hydrates tended to form in the vicinity of the position where $\mathrm{CO}_{2}$ injection such as the dense hydrate formed near the reactor bottom if $\mathrm{CO}_{2}$ injection from the bottom channel. Though further investigations are needed on the detailed mechanism of the "triggering method" of $\mathrm{CO}_{2}$ injection by more characteristic or modeling means, this simplistic and efficient method provides a potential way for controlling the hydrate-based gas storage and transportation process.

\section{Notes}

The authors declare no competing financial interest.

\section{Acknowledgement}

The financial was supported by the National Science and Technology Pillar Program (20140015), Qingdao Science and Technology and People's Livelihood Project (14-2-3-69-nsh) and The Integrated and Industrialized Research of the Gasified Grainbased Residuals (2014BAC31B01).

\section{References}

[1] Sloan ED. Clathrate hydrate of natural gases. 3rd ed. New York: Marcel Dekker; 2007.

[2] Yevi GY, Rogers RE. Storage of fuel in hydrates for natural gas vehicles (NGVs). J Energy Resour ASME 1996;118:209-13.
[3] Wang F, Liu GQ Meng HL, Guo G, Luo SJ, Guo RB. Improved methane hydrate formation and dissociation with nanosphere-based fixed surfactants as promoters. ACS Sustainable Chem Eng 2016;4:2107-13.

[4] Chatti I, Delahaye A, Fournaison L, Petitet JP. Benefits and drawbacks of clathrate hydrates: a review of their areas of interest. Energy Convers Manage 2005;46:1333-43.

[5] Li HJ, Wang LG. Hydrophobized particles can accelerate nucleation of clathrate hydrates. Fuel 2015;140:440-5.

[6] Zhong DL, Lu YY, Sun DJ, Zhao WL, Li Z. Performance evaluation of methane separation from coal mine gas by gas hydrate formation in a stirred reactor and in a fixed bed of silica sand. Fuel 2015;143:586-94.

[7] Zhou CY, Hao WF, Feng ZP. Shortening the induction period of forming gas hydrate by orifice bubbling method. Nat Gas Ind 2005;25:27-9.

[8] Li G, Liu DP, Xie YM, Xiao Y. Study on effect factors for $\mathrm{CO}_{2}$ hydrate rapid formation in a water-spraying apparatus. Energy Fuels 2010;24:4590-7.

[9] Wang HX, Zhou XT. Research progress of gas hydrate promoter. Mod Chem Ind 2013;33:28-31.

[10] Gilanyi T, Wolfram E. Interaction of surfactants with polymers in aqueoussolution. Magy Kem Foly 1982:88:404-10.

[11] Mori YH. Recent advances in hydrate-based technologies for natural gas storage-a review. J Chem Ind Eng 2003;54:1-17.

[12] Ripmeester JA. Low-temperature cross-polarization/magic angle spinning ${ }^{13} \mathrm{C}$ NMR of solid methane hydrates: structure, cage occupancy, and hydration number. Phys Chem Chem Phys 1988;92:337-9.

[13] Uchida T, Moriwaki M, Takeya S, Ikuko IY, Ohmura R, Nagao J, et al. Two-step formation of methane-propane mixed gas hydrates in a batch-type reactor. AIChE J 2004;50:518-23.

[14] Eslamimanesh A, Babaee S, Gharagheizi F, Javanmardi J, Mohammadi AH, Richon D. Assessment of clathrate hydrate phase equilibrium data for $\mathrm{CO}_{2}+\mathrm{CH}_{4} / \mathrm{N}_{2}+$ water system. Fluid Phase Equilib 2013;349:71-82.

[15] Pahlavanzadeh H, Khanlarkhani M, Mohammadi AH. Clathrate hydrate formation in (methane, carbon dioxide or nitrogen + tetrahydropyran or furan + water) system: thermodynamic and kinetic study. J Chem Thermodyn 2016;92:168-74.

[16] Sfaxi IBA, Belandria V, Mohammadi AH, Lugo R, Richon D. Phase equilibria of $\mathrm{CO}_{2}+\mathrm{N}_{2}$ and $\mathrm{CO}_{2}+\mathrm{CH}_{4}$ clathrate hydrates: experimental measurements and thermodynamic modelling. Chem Eng Sci 2012;84:602-11.

[17] Sun Y, Xue Q, Zhou Y, Zhou L. Sorption equilibria of $\mathrm{CO}_{2} / \mathrm{CH}_{4}$ mixture on activated carbon in presence of water. J Colloid Interface Sci 2008;322:22-6.

[18] Yi L, Liang D, Zhou X, Li D. Molecular dynamics simulations for the growth of $\mathrm{CH}_{4}-\mathrm{CO}_{2}$ mixed hydrate. J Energy Chem 2014;23:747-54.

[19] He Y, Rudolph ESJ, Zitha PLJ, Golombok M. Kinetics of $\mathrm{CO}_{2}$ and methane hydrate formation: an experimental analysis in the bulk phase. Fuel 2011:90:272-9.

[20] Bruusgaard H, Servio P. Prediction of methane and carbon dioxide solubilities for the $\mathrm{CH}_{4}+\mathrm{CO}_{2}+\mathrm{H}_{2} \mathrm{O}$ system under hydrate-liquid-vapor equilibrium. Fluid Phase Equilib 2011:305:97-100.

[21] Geng CY, Wen H, Zhou H. Molecular simulation of the potential of methane reoccupation during the replacement of methane hydrate by $\mathrm{CO}_{2}$. J Phys Chem A 2009;113:5463-9.

[22] Wang F, Jia ZZ, Luo SJ, Fu SF, Wang L, Shi XS, et al. Effects of different anionic surfactants on methane hydrate formation. Chem Eng Sci 2015;137:896-903.

[23] Lo C, Zhang JS, Somasundaran P, Lee JW. Investigations of surfactant effects on gas hydrate formation via infrared spectroscopy. J Colloid Interface Sci 2012;376:173-6.

[24] Yoslim J, Linga P, Englezos P. Enhanced growth of methane-propane clathrate hydrate crystals with sodium dodecyl sulfate, sodium tetradecyl sulfate, and sodium hexadecyl sulfate surfactants. J Cryst Growth 2010;313:68-80.

[25] Ma ZW, Zhang P, Bao HS, Deng S. Review of fundamental properties of $\mathrm{CO}_{2}$ hydrates and $\mathrm{CO}_{2}$ capture and separation using hydration method. Renewable Sustainable Energy Rev 2016;53:1273-302.

[26] Ricaurte M, Torré JP, Diaz J, Dicharry C. In situ injection of THF to trigger gas hydrate crystallization: application to the evaluation of a kinetic hydrate promoter. Chem Eng Res Des 2014;92:1674-80.

[27] National Natural Gas Standardization Technical Committee, National Standards of People's Republic of China. in: Compulsory national standard GB17820-2012 "Natural Gas"; 2012.

[28] van der Waals JH, Platteeuw JC. Clathrate solutions. Adv Chem Phys 1959;2:1-57.

[29] Jacobson LC, Hujo W, Molinero V. Nucleation pathways of clathrate hydrates: effects of guest size and solubility. J Phys Chem B 2010;114:13796-807.

[30] Uchida T, Ikuko IY, Takeya S, Kamata Y, Ohmura R, Nagao J, et al. Kinetics and stability of $\mathrm{CH}_{4}-\mathrm{CO}_{2}$ mixed gas hydrates during formation and long-term storage. ChemPhysChem 2005;6:646-54.

[31] Herri JM, Kwaterski M. Derivation of a Langmuir type of model to describe the intrinsic growth rate of gas hydrates during crystallisation from gas mixtures. Chem Eng Sci 2012;81:28-37.

[32] Zhou XB, Liang DQ, Yi LZ. Experimental study of mixed $\mathrm{CH}_{4} / \mathrm{CO}_{2}$ hydrate formation kinetics and modeling. Asia-Pac J Chem Eng 2014;9:886-94.

[33] Wang F, Fu SF, Guo G, Jia ZZ, Luo SJ, Guo RB. Experimental study on hydratebased $\mathrm{CO}_{2}$ removal from $\mathrm{CH}_{4} / \mathrm{CO}_{2}$ mixture. Energy 2016;104:76-84. 